\title{
Building Consensual Institutions: Networks and the National Estuary Program
}

\author{
Mark Schneider State University of New York, Stony Brook \\ John Scholz Florida State University \\ Mark Lubell University of California, Davis \\ Denisa Mindruta State University of New York, Stony Brook \\ Matthew Edwardsen State University of New York, Stony Brook
}

\begin{abstract}
Currently, many approaches to solving policy problems seek to create community-based, less coercive solutions that are creating the conditions for the birth of new regional governmental institutions. We argue that networks form the core of these emergent structures and that federal programs can play a positive role in developing local networks. Our empirical work compares networks in estuaries included in National Estuary Program with networks in comparable estuaries that were not. We find that the networks in NEP areas span more levels of government, integrate more experts into policy discussions, nurture stronger interpersonal ties between stakeholders, and create greater faith in the procedural fairness of local policy, thus laying the foundation for a new form of cooperative governance.
\end{abstract}

A wide range of policy domains are characterized by political and administrative jurisdictions that are poorly suited for solving many emerging problems. This is particularly true in the area of environmental policy, where the physical boundaries of watersheds, airsheds, fishing grounds, and other natural systems typically cross local political and administrative boundaries. The need to deal with problems that transcend established governmental structures has intensified at the same time that the zeitgeist of American politics has increasingly spurned anything that smacks of "big government." In turn, approaches that rely on hierarchical commandand-control are being replaced by policies that seek to create more community-based and less coercive solutions to policy problems. This has created the conditions for the birth of new regional governmental institutions that differ dramatically from traditional large-scale governmental organizations.
While political scientists often define government institutions by the formal structures that determine the authoritative allocation of resources, we argue that networks form the core of these new governing structures. These purposeful networks evolve across administrative and political boundaries and provide a potential alternative to more formalized, hierarchical coordination mechanisms (Bardach 1998). Our perspective follows Heclo, who notes that: ". . .it is through networks of people who regard each other as knowledgeable, or at least needing to be answered, that public policy issues tend to be refined, evidence debated, and alternative options worked out - though rarely in any controlled, well-organized way" (Heclo 1978; also see Bardach 1998).

Network-based structures are characterized by high levels of interdependence involving multiple organizations, where formal lines of authority are blurred and where diverse policy actors are knitted together to focus

Mark Schneider is Professor of Political Science, State University of New York, Stony Brook, NY 11794-4392 (mark.schneider@stonybrook. edu). John Scholz is the Francis Eppes Professor of Political Science, Florida State University, Tallahassee, FL 32306-2230 (john.scholz@fsu.edu). Mark Lubell is Assistant Professor of Environmental Science and Policy, One Shields Avenue, University of California, Davis, CA 95616. Denisa Mindruta is a Ph.D. candidate in the Department of Political Science, State University of New York, Stony Brook, NY 11794-4392. Matthew Edwardsen graduated with his BA degree from the Department of Political Science, State University of New York, Stony Brook, NY 11794-4392 and is now serving in the Peace Corps.

This research was supported by NSF (Grant SBR97295905) and NSF/EPA (Grant SBR9815473). We would also like to acknowledge the extensive support given to our work by the staff of the National Estuary Program and many of the local NEPs, especially Tampa Bay.

American Journal of Political Science, Vol. 47, No. 1, January 2003, Pp. 143-158

(C) 2003 by the Midwest Political Science Association

ISSN 0092-5853 
on common problems (John 1994; Knoke et al. 1996; Konig and Brauninger 1998; O’Toole 1997). By spanning the political, administrative, and ideological boundaries that characterize the fragmented and adversarial federalist system, networks can stimulate collaboration and cooperation through information and reputation effects that encourage the development of common perspectives on policy issues and norms of cooperation and trust (Lin 2001). The resulting formal and informal interactions have the potential to increase policy effectiveness at less cost than authority-based structural changes arrived at through formal reorganization (see especially Bardach 1998; also Heclo 1978; Provan and Milward 1995).

The substantive focus for our study is the emergence of governance networks in an increasingly important environmental "commons": estuaries, which are coastal watersheds where freshwater flows into saltwater bodies. Estuaries are often quite large, almost always spanning multiple local and often state governmental jurisdictions; they are important as sources of food, recreation, biodiversity, and waste disposal; they are under increasing stress, especially from development; and consequently, they are in need of coordinated policies involving a wide range of actors drawn from the private and nonprofit sectors, as well as elected and appointed public officials drawn from multiple governments at different levels. Indeed, an array of multi-actor "partnerships" is gradually emerging to coordinate policies in estuary and other watershed areas, encouraged in part by federal and state policies. ${ }^{1}$ One such policy, the United State Environmental Protection Agency's National Estuary Program (NEP), provides the milieu in which we study the development of local policy networks.

Ultimately, we will assess the marginal contribution of the NEP and the networks it encouraged to estuary policy outcomes; however, our goal in this article is more modest. The NEP provides a research site to examine the extent to which the NEP has changed the quality of networks by studying their size and composition, the nature of interactions between network members, and whether

\footnotetext{
${ }^{1}$ These partnership agreements appear under many names: "sustainable development" (Rabe and Zimmerman 1997), "ecosystem management" (Burroughs and Clark 1995), "grassroots ecological democracy" (Hartig and Zarull 1992), or "integrated environmental management" (Rabe 1996). Several recent studies describe specific programs featuring community agreements as a major component, including Habitat Conservation Plans under the auspices of the 1973 Endangered Species Act (Beatley 1991, 1992), Remedial Action Plans in the Great Lakes (Hartig and Zarull 1992; MacKenzie 1996), and Natural Communities Conservation Planning in California (Wheeler 1996). Associated with these programs are the ideas of environmental dispute resolution and negotiated rulemaking designed to reduce the rancor and uncertainty in natural resource conflicts (Coglianese 1997).
}

or not individual attitudes signal underlying levels of cooperation.

In the next section, we develop a contractual perspective on local policy networks as public goods. We argue that networks can help resolve current problems of watersheds and natural resource governance, but they are undersupplied because the costs of creating and maintaining networks are high and the benefits gained by the policy community as a whole are not reflected in the incentives of individual stakeholders. After developing this perspective, we then discuss our quasi-experimental research design that compares the extent and quality of networks in NEP estuaries with those in a matched set of estuary areas that are not part of the NEP. We also compare attitudes among participants in the policy process (or "stakeholders" to use current terminology) in the two areas to assess further the role of networks in creating a basis for cooperation. The conclusion summarizes the role of local policy networks in the United States federalist system and the possibilities that federal and state policies can strengthen that role.

\section{Networks, Collaboration, and the Problem of Undersupply}

Political contracting theories of collective action argue that the benefits of networks flow from their ability to allow individuals to make mutually beneficial exchanges and agreements that otherwise would not take place (see especially Rauch and Casella 2001; also see Granovetter 1985). Networks enhance the likelihood and scope of policy agreements by increasing available information about potential agreements and enhancing the credibility of commitments to fulfill the agreements. By spanning organizational boundaries in fragmented policy arenas, networks provide information about the myriad details of organizational decision making as well as potential implementation problems in each organization, which allows stakeholders to develop previously unexplored opportunities for collaboration. Networks increase the credibility of commitments by transforming short-term interactions into repeated games in which a reputation for reciprocity and trustworthiness can potentially mitigate the problem of opportunism involved in single exchanges (Rauch and Casella 2001).

However, the flow of network benefits to individual participants and the policy community are constrained by the costs of developing and maintaining contacts, which the contract perspective refers to as transaction costs (Lubell et al. 2002). Time and effort are required to locate, cultivate, and maintain contacts outside the organization, 
and it is uncertain which if any contacts will ultimately be useful. The costs of network development are exacerbated by the structure of federalism in the United States, which creates vertical fragmentation between levels of the federal system and horizontal fragmentation between local jurisdictions in a specific geographic location such as an estuary. Furthermore, the highly adversarial character of traditional environmental policy has created a legacy of conflicting environmental and developmental advocacy coalitions, where the tight-knit networks and shared belief systems within each coalition inhibit cooperation between them (Sabatier and Jenkins-Smith 1993; Zafonte and Sabatier 1998). The transaction costs of developing networks in complex, fragmented, adversarial policy arenas impede the development of networks and integrated institutions that span estuaries and other regional ecosystems, to the detriment of environmental and development interests alike (Marsh and Lallas 1995).

These impediments are exacerbated by another problem: Individual incentives do not reflect the full benefits of the contacts cultivated within the estuary policy community, since an additional contact increases the information and reputation resources for all others in the network without any additional investment by the others. Furthermore, partnerships, discussion forums, and other local collaborative efforts that could reduce transaction costs are public goods that aid the policy community as a whole more than they aid any individual stakeholders, so individual incentives will generally lead to an underinvestment in such efforts. This leads to the second-level collective action problem of institutional undersupply discussed by Ostrom (1990). We next consider the potential role of federal and state programs in resolving this secondlevel collective action problem.

\section{Can the National Estuary Program Enhance Local Networks?}

The 1987 amendments to the Clean Water Act created the National Estuary Program (NEP). Estuaries that met the EPA criteria and were nominated by their state could apply for NEP status. The 28 estuaries accepted into the NEP program received 3 to 5 years of financial and technical support to develop an integrated Comprehensive Conservation Management Plan (CCMP) for the estuary. The CCMP planning process entailed the creation of a management conference that involved representatives from federal, state, and local government agencies responsible for managing the estuary's resources, as well as interest group representatives, citizens, business leaders, educators, and researchers. The process emphasized public participation and the need for a broad consensus among all participants.

The meetings to draft the CCMP initially stimulated broader, more frequent contacts among stakeholders and generated increasing momentum to continue interactions. For example, many participants in the NEP planning process whom we interviewed noted that the frequency of meetings and emphasis on participation brought about a growing pressure to succeed, which in turn led to a psychology of consensus, agreement, and "ownership" of collective outcomes (cf. Wondolleck and Yaffee 2000). They also reflected the common demand in many communities for policies that enhance environmental quality and the growing aversion to authority-based command-and-control policies, which provided fertile ground for the emergence of networks linking diverse stakeholders into more cooperative, network-based governance structures (Melbeck 1998, 534).

But getting already busy stakeholders to participate in a new, untried process with no clear sign of success would have been considerably more difficult without several important ingredients provided by the NEP that reduced the costs of network development and maintenance. Among the most important were:

- Monetary resources for committee staff, workshops, demonstration projects, and technical studies, all of which provided a clear focal point for collective concerns on estuary matters sufficient to engage the attention of otherwise skeptical individuals and organizations.

- A newly defined policy and geographic boundary that encouraged contact between organizations dealing with interrelated, acute, unresolved policy problems.

- A forum for deliberation and negotiations with statutory legitimacy based on an act of Congress. Ostrom (1990) found such authoritative legitimacy to be a key ingredient for successful local institutions.

- A source of successful institutional examples and collaborative projects for later programs provided by the early NEP programs, and a national NEP office and national organization of NEP managers (Association of National Estuary Programs) to enhance diffusion of information across estuary boundaries.

- A public participation requirement to qualify for monetary resources, which exposed competing coalitions to repeated interactions across traditional lines of advocacy.

Our empirical study analyzes the extent to which the incentives provided by the NEP have created stronger networks and more cooperative attitudes in NEP 
estuaries that may provide a foundation for continued collective action even after the CCMP development process has ended. To do so, we focus in particular on four potential boundaries within local policy communities that may be spanned by extended networks.

First, vertical boundary-spanning networks integrate agencies at multiple levels of government. These informal connections can improve coordination across federal, state, regional, and local agencies that otherwise may be working at cross-purposes-coordinating the federal flood control program and local habitat restoration efforts may lead to positive benefits for both. Research on intergovernmental relations has long identified the importance of these vertical networks in the U.S. federal system (e.g., Peterson 1995; Schneider 1989).

Second, horizontal boundary-spanning networks integrate local jurisdictions operating within a geographically defined area (Ostrom 1972). Local governments are often the frontline players most directly affected by the condition of the estuary, but their attempts to improve conditions are impeded by collective action problems between competing jurisdictions. For example, costly controls on storm water runoff to reduce toxic and nitrogen pollution may make sense for the estuary as a whole, but are less sensible for any single jurisdiction unless other jurisdictions impose similar controls.

Third, expertise-spanning networks can link external sources of policy expertise into existing networks of interest groups and administrators charged with implementing policies (Zafonte and Sabatier 1998). Partly in response to the widespread recognition of estuary problems, the past decades have witnessed dramatic increases in the number of experts on estuary-related topics housed in universities, research stations, and private consultant firms located in or near the estuaries. Implementation networks connect experts with implementation authorities to increase the likelihood that available information is correctly interpreted and incorporated into implementation decisions.

Fourth and finally, ideological boundary-spanning networks can provide the basis for negotiated agreements between interests that diminish problems associated with adversarial coalitions. Instead of forcing stakeholders to choose sides and confront each other in courts and legislatures, opposing interests involved in the same networks can gain informal representation of interests directly in estuary decision processes. By developing long-term interactions across coalitions, norms of reciprocity and trust could develop between traditional adversaries. Thus, network-based governance is most effective to the extent that networks span interest boundaries by including both environmental and development organizations.

\section{Research Design and Data}

For a better sense of the policy space in which these new institutional structures are being formed - what Ostrom (1990) calls the "action arena"-consider the Tampa Bay Estuary Program (TBEP) in Florida. This program covers 2,200 square miles and cuts across five different counties (Hillsborough, Polk, Pinellas, Sarasota, and Manatee). Within these counties, the TBEP includes three large cities (Tampa, St. Petersburg, and Clearwater), and a large number of smaller municipalities (e.g., Temple Terrace and Plant City, both in Hillsborough County) and special districts (for example, the Hillsborough County Port District). Besides these local governments, the state of Florida has multiple agencies with major functional responsibility for various policies affecting the estuary (such as Florida Department of Environmental Protection, Southwest Florida Water Management District, and Tampa Bay Regional Planning Council), as does the federal government, where the Army Corp of Engineers, the Environmental Protection Agency, and U.S. Fish and Wildlife Service have major roles. $^{2}$

In order to compare the networks in NEP and nonNEP estuaries, we conducted a survey in 12 NEP estuaries and 10 non-NEP estuaries selected from NOAA's Coastal Assessment Framework to match the regional distribution and the physical characteristics of the NEP estuaries. ${ }^{3}$ Our goal was to identify a set of non-NEP estuaries similar enough to the NEPs in our sample to act as a control group. Appendix A lists the estuaries in the study. In selecting the NEP sites, we tried to ensure both geographical diversity and a distribution across the cohorts of estuaries accepted into the NEP program. After we selected the NEP areas, we then generated a list of matching estuaries that were not part of the NEP program, with the match based on geographic proximity, watershed condition, agricultural runoff potential, population density, and per capita income. However, because the EPA tended to select the largest and best-known estuaries along any given coastline, it was impossible to perfectly match NEP and non-NEP estuaries along these criteria. We will discuss this problem in more detail in the section on non-random selection.

\footnotetext{
${ }^{2}$ For more information and a map of the TBEP, visit http://www. tbep.org/index.html.

${ }^{3}$ For maps showing the distribution of these watersheds across the United States coastal areas, and for more information on how estuary boundaries are determined, see http://sposerver. nos.noaa.gov/projects/caf/caf.html.
} 
TABLE 1 Characteristics of NEP and Non-NEP Areas

\begin{tabular}{|c|c|c|c|c|c|c|}
\hline Estuary Characteristics & NEPs & Non-NEPs & t-test (2-tail) & $\begin{array}{c}\text { NEPs } \\
\text { (Sample) }\end{array}$ & $\begin{array}{c}\text { Non-NEPs } \\
\text { (Sample) }\end{array}$ & t-test (2-tail) \\
\hline Stress on estuary & .58 & .48 & 1.93 & .68 & .56 & .78 \\
\hline Farm concentration & .01 & 0.02 & 2.86 & .00 & .01 & .65 \\
\hline Population density (thousands) & .73 & .32 & 2.03 & .32 & .10 & 1.99 \\
\hline Population (million) & 3.54 & 2.90 & 5.21 & 1.99 & 0.35 & 1.40 \\
\hline (log population) & $(13.67)$ & $(11.20)$ & $(4.15)$ & $(13.49)$ & $(11.99)$ & $(2.11)$ \\
\hline Proportion black & .10 & .12 & .81 & .11 & .14 & .51 \\
\hline Median income (thousands) & $\$ 31.73$ & 26.70 & 3.52 & 29.22 & 25.47 & 1.84 \\
\hline Previous partnerships & .13 & .01 & 2.48 & .006 & .00 & 1.24 \\
\hline Prior federal program & .39 & .03 & 2.30 & .68 & .02 & 1.83 \\
\hline Area (thousands square miles) & 7.78 & 7.15 & .07 & 9.84 & 2.81 & 1.42 \\
\hline Number of major estuaries & 27 & 78 & & 10 & 12 & \\
\hline
\end{tabular}

Notes: t-test of difference in mean between groups assumes unequal variance. Data are from NOAA Coastal Assessment Framework (CAF) data, available at http://sposerver.nos.noaa.gov:80/projects/caf/caf.html.

\section{Identifying Stakeholders}

With our study areas chosen, we needed to identify the stakeholders in each estuary. The NEP planning process required a compilation of all active stakeholders and these lists, obtained from each NEP in the study, provided the sampling frame for the survey of that estuary. In order to generate as large a response rate as possible with available funding, we first mailed questionnaires to those in the sample. We then followed up with telephone interviews of nonrespondents to the mail survey.

Since we had no lists of stakeholders in the non-NEP estuaries, we used a different strategy. We first contacted the federal and state government agencies and interest groups in the estuaries to develop a list of 10-20 "seed" interviews. We then contacted stakeholders on this list by telephone. In addition to generating substantive information about networks and policy practices, the interviews were designed to generate the names of up to three additional stakeholders, who we interviewed in a second round. This snowball process continued until no new names were generated or the target of 30 interviews in each estuary area was completed.

The resulting sample sizes and response rates for the mail, telephone, and snowball phases of the survey are listed in Appendix A. Analysis of the mail and telephone survey in NEP estuaries produced few significant differences in mean responses, suggesting that there is little problem with different response biases in telephone and mail surveys. Consequently, we combined the results of the telephone and mail surveys for the following analyses.

One limitation of our sampling technique deserves attention. As we see in the results section, the average number of respondents is greater in NEP areas than nonNEP ones. Based on elite interviews with participants in both areas, we argue that the greater number of respondents identified and interviewed in NEP arenas reflects the larger universe of participants activated by the processes of the NEP. In non-NEP areas, we began with an initial list constructed to ensure representation of elected and agency officials as well as development and environmental interests. Our snowball techniques aggressively sought to identify and interview as many participants in these areas as possible. However, if the snowball technique used in non-NEP arenas was less effective in identifying policy participants than the NEP list-creation process, and if the resultant sample therefore represented a smaller proportion of the universe, some of the differences discussed below might be attributable to sampling techniques. ${ }^{4}$

\section{The Non-Random Selection Problem}

The EPA granted NEP status to 27 estuaries in the continental United States, or approximately one quarter of the major estuaries. In the first set of columns in Table 1,

\footnotetext{
${ }^{4}$ For example, Burt (1983) warns that a sample representing k percent of the total universe of network participants in an area is likely to reduce the numbers of network contacts detected to $\mathrm{k}$ percent of total contacts. Burt's warning addressed the problem of using small percentage samples of general populations, whereas our survey respondents represent over half of the listed stakeholders in NEP estuaries and probably a higher proportion of active stakeholders in non-NEP estuaries. In any case, this potential problem affects only the initial comparison of the numbers of networks discussed in the next section, and does not affect the comparison of the proportions of different types of stakeholders in networks or in other measures of the quality of networks.
} 
we compare characteristics of the NEP estuaries with the remaining 78 large estuary areas for which data were available. In the last three columns we compare the NEP areas in our sample to the set of non-NEP areas we chose as close matches in our quasi-experimental design.

These data present greater descriptive detail about the areas in our study, but they also introduce a problem - the set of estuaries that successfully became part of the NEP program are not a random sample of all major estuary areas. Note for example in comparing the NEP areas to the 78 other areas that the NEP ones are less rural, larger in population, of higher population density, and more affluent. They also had more previous experience with creating partnerships prior to the NEP and had greater involvement in other federal programs (as reflected in the number of soil and water conservation districts in the area). Note too that in the smaller set of estuaries included in our sample, the pattern of differences is quite similar to the pattern among all estuaries, but that given the smaller number of observations and that these nonNEP areas were chosen to match the NEP areas on as many dimensions as possible, most of the differences are not statistically significant.

Many of the factors that distinguish the NEP from non-NEP areas in our sample and in the nation as a whole reflect transaction costs related to the development of networks and other voluntary associations (Lubell et al. 2002), raising the possibility that estuaries that won NEP designation may have already had better developed policy networks-indeed, the better developed policy networks may account for the selection of NEPs. This could mean that any present differences observed in the quality of networks in NEP and non-NEP estuaries are artifacts of previous conditions and do not reflect any independent contribution of the NEP program. Hence, we use statistical models to control for the possibility of non-random selection in quasi-experimental design (Achen 1986), as presented in the results section.

\section{Identifying Networks}

Following Heclo (1978), the networks we study are built around the routine, deliberate contacts among people who regard each other as knowledgeable about public policy issues in order to work out options, debate evidence, and discover alternative options. We observe this set of contacts in each estuary through the eyes of policy participants by asking them for the names and organizations of individuals they routinely contact to discuss estuary matters. To simplify analysis, each mention of a discussant is treated as a contact between the respondent's and the discussant's organization. ${ }^{5}$

We begin by examining networks using Heclo's perspective on the overall pattern of contacts in a given policy arena. Figures 1 and 2 display the contacts between stakeholders (via "sociograms") in one non-NEP (St. Andrews Bay, FL) and one NEP estuary (Tampa Bay, FL). Each line in the sociogram represents at least one contact between the organizations listed, and all contacts between any two organizations mentioned in the survey are represented.

These sociograms graphically illustrate the hypothesized differences in patterns of network contacts to be found in NEP and non-NEP areas. In Tampa Bay, we can quite literally see a dense web of relationships in which stakeholder organizations are more tightly intertwined with one another (see Figure 1). In contrast, the links between stakeholders in St. Andrews are fewer in number and the density of relationships much thinner (see Figure 2).

Within this full set of policy contacts, Knoke and Kuklinski emphasize the need to analyze "intermediate structures in which some actors are more extensively connected among themselves than are others" (1991, 175; cf. Knoke et al. 1996). Scott (1991) argues that cliquelevel analysis is most appropriate to capture this intensity and regularity of interactions, and that the "2-clan" concept is the best available operationalization in network analysis.

Clans are compact subgroups within the wider policy arena in which all individuals are in close contact with each other. More specifically, the 2-clan is a subset of actors for which every pair is connected either directly or through a single intermediary. Each clan is defined as the smallest self-contained subset. It cannot fully contain other clans, even though it frequently shares overlapping membership with other clans. Since no member is more than two links removed from any other clan member, the clan is small enough for reputation effects to support credible commitments. At the same time, two links are sufficient to include the most common size of "weak-tie" networks that Granovetter (1974) found effective for individuals searching for information about jobs. We use the UCINET program to identify all clans in each estuary based on

\footnotetext{
${ }^{5}$ Scholars debate the precise methodology by which to generate information about networks, but our technique of asking a respondent to describe their discussants is common. See, e.g., Marsden 1985; Burt 1987; Arabie and Wind 1994; Huckfeldt and Sprague 1995; Schneider et al. 1997b. The organizational rather than individual basis of our analysis also reflects the respondents' predilection to report the organizational affiliation of their discussants while often not giving specific names of contacts.
} 


\section{FIGURE 1 Networks Are Denser in NEP Areas: The Case of Tampa Bay}

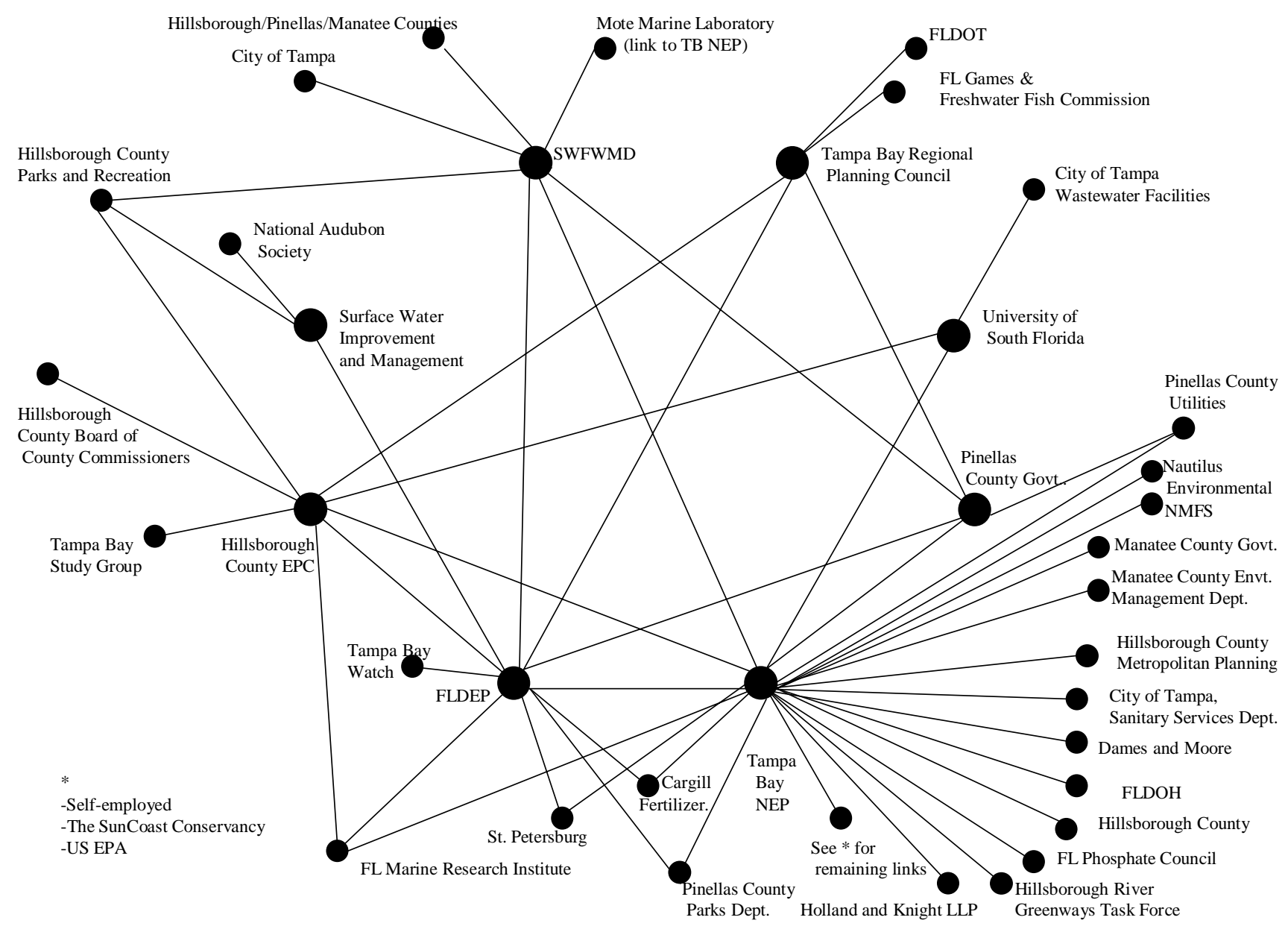

the matrix of contacts between organizations and compare the composition of clans in NEP and non-NEP estuaries.

Despite an impressive methodological sophistication, network analysis provides no consensus on the most appropriate concepts or the best technique for testing differences in network structure and quality across different geographic areas (Scott 1991). Consequently, we employ multiple levels of analysis to provide a robust test of our hypotheses about the difference in boundary-spanning networks between NEP and non-NEP estuaries.

We first analyze the overall patterns of contact, comparing the numbers of clans, organizations, and contacts within each estuary. We next analyze the boundaryspanning properties of clans identified in each estuary by comparing the proportion of clans that span various boundaries. We then analyze the frequency and ideological similarity of dyadic contacts, and finally compare individual stakeholder attitudes and beliefs related to network contacts and estuary policy effectiveness.

\section{Comparing Networks}

In the first panel of Table 2, we compare the networks in the NEP and non-NEP areas in our sample using a simple OLS regression model, where the dependent variable is the number of clans and a dummy variable $[0=$ nonNEP, $1=\mathrm{NEP}$ ] is the only independent variable. This simple analysis is equivalent to a t-test of the difference between means. In this "naïve" analysis, we find that a simple NEP dummy has a large statistically significant effect on the number of networks found-in contrast to the predicted 7.8 networks in non-NEPs, there were, on average, over 25 networks found in NEP areas. ${ }^{6}$ This simple analysis confirms the differences in organizational density visually displayed in Figures 1 and 2. But because of the problem of non-random selection into the NEP, in the second panel in Table 2, we introduce our method of

${ }^{6}$ This is simply the sum of the constant (7.8) plus the coefficient on the NEP dummy variable. 


\section{FIGURE 2 Non-NEP Areas Have "Thinner" Networks: The Case of St. Andrews}

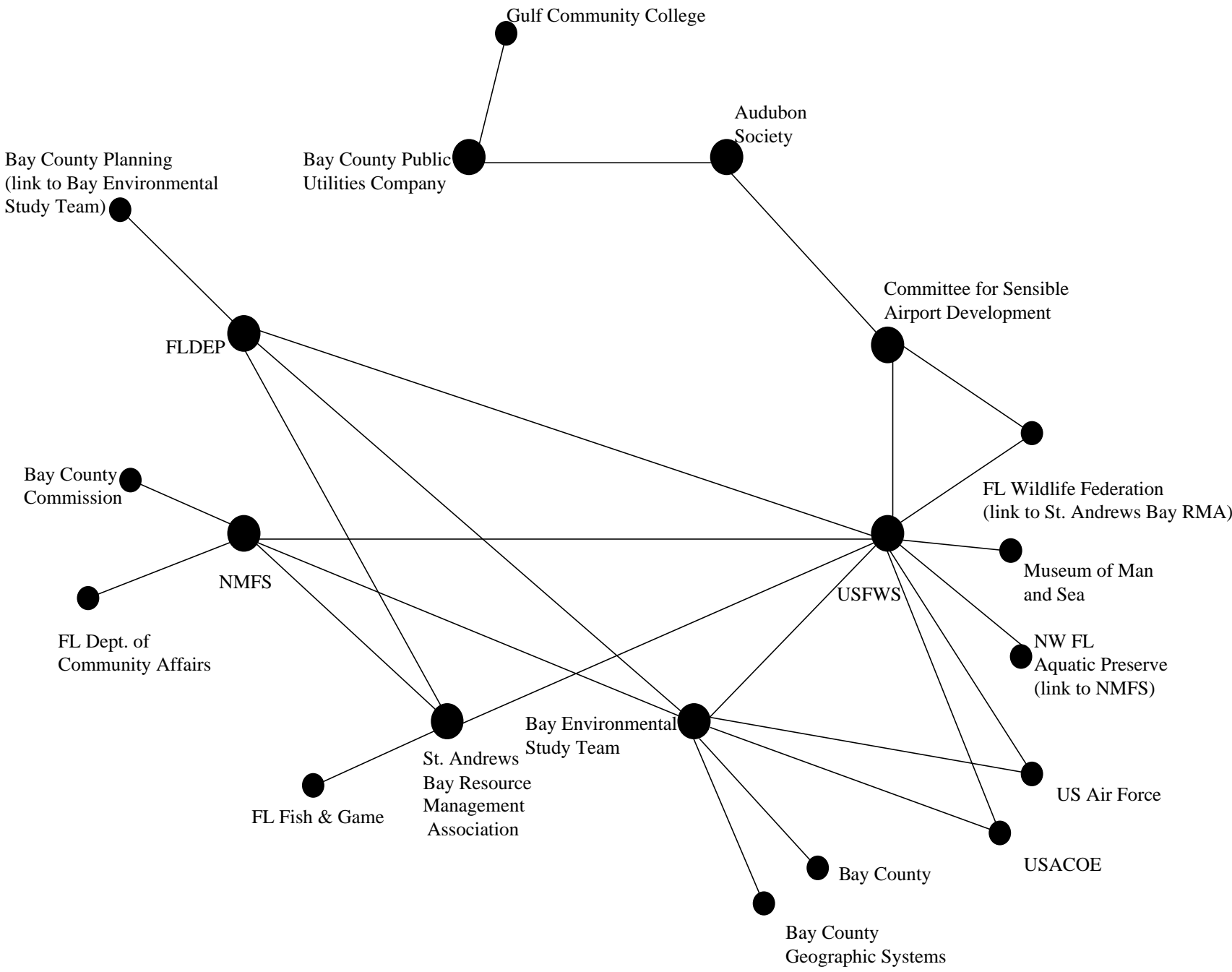

controlling for potential bias because of selection for the NEP "treatment."

The treatment effect bias arises when the error terms are correlated across the two equations, suggesting, for example, that some unmeasured variable affects both networks and the treatment selection process. If unmeasured variables account for both enhanced networks and for NEP status, the effect of these variables on networks will be spuriously attributed to the NEP status, leading to an artificially inflated slope coefficient for the NEP dummy variable. Our analyses uses a slightly-modified version of Heckman's two-stage estimation process to account for the remaining non-random process involved in selecting the "treatment" - in our case, membership in the NEP program (Achen 1986; Greene 1999). The first stage of our estimation process uses the factors listed in Table 1 to predict the occurrence of NEPs among all major estu- aries in the continental United States. The second stage estimates the "treatment effect" - the impact of the NEP on network characteristics-with the coefficient of the dummy NEP status variable providing an estimate and a significance test of the differences between NEP and non-NEP estuaries. By controlling for the selection of NEP estuaries, we are able to isolate the marginal impact of the NEP on networks from the factors that lead to placement of the NEP in an estuary in the first place.

First, the selection equation predicting NEP status is significant and has a 55 percent proportional reduction of error. While we do not focus here on the substantive interpretation of the selection equation, ${ }^{7}$ we note that the

${ }^{7}$ For an analysis of the factors influencing the creation of partnerships similar to NEPs, see Lubell et al. 2002. 


\section{TABle 2 There Are More Clans in NEP Areas}

\begin{tabular}{lcc}
\hline “Naïve" OLS Model (number of clans) & \\
\hline & Coefficient & Standard error \\
NEP status & 17.86 & 3.76 \\
Constant & 7.89 & 2.84 \\
$\mathrm{R}^{2}$ & .52 & \\
Number of observations & 22 & \\
& & \\
\hline
\end{tabular}

Treatment Corrected Model

\begin{tabular}{lcc}
\hline Selection Equation & & \\
& Coefficient & Standard error \\
Stress on estuary & .35 & .57 \\
Farm concentration & 8.75 & 15.58 \\
Population density (000) & -.85 & .33 \\
Population (log) & .58 & .16 \\
Proportion black & -2.87 & 2.03 \\
Median income (000) & .08 & .03 \\
Previous partnerships & 6.13 & 3.26 \\
Prior federal programs & 1.82 & .71 \\
Area (000) & -.02 & .01 \\
Constant & -9.78 & 2.40 \\
Proportional reduction & $55 \%$ & \\
$\quad$ in error & & \\
Chi-squared (9) & 59.25 & \\
Number of observations & 105 & \\
Outcome Equation (number of clans) & \\
$\quad$ NEP status & 15.70 & 5.22 \\
Lambda & 2.59 & 4.49 \\
Constant & 8.80 & 3.13 \\
$\mathrm{R}^{2}$ & .50 & \\
Number of observations & 22 & \\
\hline
\end{tabular}

model is driven primarily by population size and density, median income, and prior experience with federal programs relating to water quality. To control for the potential bias indicated by this selection equation, lambda (the inverse mills ratio) is calculated and the individual value for each case is included in the treatment effect equation. The inclusion of lambda (plus appropriate corrections in standard error calculations) corrects for the potential bias from correlated errors, while the significance of lambda provides a test for correlated errors (Greene 1999; see Appendix $\mathrm{C}$ for more details.).

In the bottom panel of Table 2, we recalculate the effects of NEP status on the number of networks (as measured by clans) incorporating the information from the selection equation. The corrected coefficient for NEP status indicates a major impact of NEP status on the number

\section{TABLE 3 Networks Are “Thicker" in NEP Areas} Than in Non-NEPs

\begin{tabular}{lcc}
\hline & $\begin{array}{c}\text { Coefficient } \\
\text { (standard error) }\end{array}$ & $\begin{array}{c}\text { Significance } \\
\text { (one-tail) }\end{array}$ \\
\hline \multicolumn{3}{l}{ Total Number of } \\
Organizations \\
NEP status & $24.50(6.45)$ & \\
Lambda & $4.02(5.50)$ & .00 \\
Constant & $26.30(3.86)$ & .32 \\
Total Number of People Mentioned & .00 \\
NEP status & $98.23(28.34)$ & .00 \\
Lambda & $13.83(24.37)$ & .57 \\
Constant & $61.74(17.01)$ & .00 \\
\hline
\end{tabular}

of networks found in an area after controlling for NEP selection bias. The difference does shrink somewhat from 18 networks in the naïve analysis to just short of 16 in the corrected mode- but note that lambda is not significant, suggesting that the bias is not very important for this specific analysis.

In Table 3, we also see a pattern of wider involvement in networks in NEP areas compared to non-NEP ones. ${ }^{8}$ Specifically, 24 more organizations and close to 100 more people are involved in the identified policy networks in NEP areas compared to non-NEP areas. This is consistent with the proposition that government support can increase the number and range of networks as the basis for new institutional forms (Thatcher 1998; Schneider et al. 1997a).

In Table 4, we compare the extent to which clans in NEP and non-NEP areas span different sets of actors. For the reader's convenience, we discuss Table 4 coefficients in terms of predicted frequencies after correction for non-random selection effects. As we argue above, spanning policy gaps is a critical goal of the new consensual approach to environmental policy. We see evidence that clans in the NEP are less likely to consist solely of government officials and are more likely to span levels of government. Only 10 percent of the clans in NEPs consisted entirely of government officials, compared to 19 percent of clans in non-NEPs. ${ }^{9}$ Similarly, about 53 percent of clans in NEPs are likely to include representatives from at least three levels of local, regional, state

\footnotetext{
${ }^{8}$ Note that the selection equation is not reported here or in subsequent tables because it does not vary from Table 2, although the effects of lambda do.

${ }^{9}$ The reported percentages are the predicted values based on the coefficients reported in Table 4 . The predicted values include the lambda coefficient, with the difference between NEP and non-NEP reflecting the coefficient on the "NEP status" value.
} 


\section{TABLE 4 Networks in NEPs Are More Likely to Span a Wider Set of Interests}

\begin{tabular}{lcc}
\hline Network Contains: & $\begin{array}{c}\text { NEP Coefficient } \\
\text { (standard error) }\end{array}$ & Significance \\
\hline Spanning Government & & \\
Government Only & & \\
$\quad$ NEP status & $-.09(.05)$ & .03 \\
Lambda & $.02(.04)$ & .58 \\
$\quad$ Constant & $.17(.04)$ & .00 \\
Three Levels of Government & & \\
$\quad$ NEP status & $.18(.08)$ & .02 \\
Lambda & $-.05(.06)$ & .42 \\
Constant & $.40(.06)$ & .00 \\
Spanning Technical Expertise & & \\
Researchers \& Consultants & & .04 \\
$\quad$ NEP status & $.15(.08)$ & .02 \\
Lambda & $.15(.07)$ & .00 \\
Constant & $.34(.06)$ & \\
Spanning Interests & & .08 \\
Business \& Environmental & $.10(.07)$ & \\
NEP status & & \\
Lambda & & \\
Constant & & $.06)$ \\
\hline
\end{tabular}

Source: Survey of NEP and non-NEP stakeholders; independent variables: see Table 1. Significance levels for NEP status are one-tail, since we have hypothesized direction. For lambda, two-tailed.

and federal government, significantly higher than the 35 percent of clans in non-NEPs. Thus, estuaries participating in the NEP have more "vertical boundary-spanning" clans, and ultimately such links may help solve problems endemic to the federal structure of so many policy domains in the United States.

Another significant difference in NEP estuaries involves the integration of the scientific community of academic, governmental, and private experts into local governance. The expansion of this expert community over the past three decades of environmental policies provides one of the critical resources required to shift greater policymaking authority to the local level. Almost two-thirds of the clans in NEP estuaries include at least one expert, a significantly larger proportion than the 49 percent in the other estuaries. In the NEP process, Science/Technical Advisory Committees play a critical role in developing local knowledge and interpreting the relevance of research studies to local conditions and are one of the main avenues for creating clans with experts. These clans involving local expertise should reduce uncertainty and hence the transaction costs of negotiating mutually beneficial agreements.
In the last section of Table 4, we look at the ability of clans to span ideological interests. As is well known, one of the most important cleavages in environmental policy pits pro-development forces, most often business groups, against slow-growth advocates, most often represented by environmental interest groups (Sabatier and Jenkins-Smith 1993). Spanning this divide is a central goal of the NEP and other network-based cooperative policy approaches. We find that clans within NEP areas are more likely than those in non-NEP areas to contain members from the other sector, although the evidence is not as strong (at $p<.08$ ) as for the other measures.

In short, our findings are consistent with the hypothesis that the NEP has provided the support for the creation of more networks. Perhaps more importantly, NEP clans appear more likely than non-NEP clans to span the jurisdictional divide between government units, integrate more experts into the estuary action arena, and include both environmental and development interests.

\section{Do Networks Build Cooperation?}

The advantages of networks depend not only on who is involved, but also on the extent to which contacts actually bring about greater trust and consensus among those who interact with one another. We argue that the emergence of trust and norms of cooperation based on repeated interactions can foster collective action in policy communities even in the presence of conflicting values and beliefs. In this, we follow Putnam's observation that networks "...foster sturdy norms of generalized reciprocity and encourage the emergence of social trust. Such networks facilitate coordination and communication, amplify reputations, and thus allow dilemmas of collective action to be resolved" (Putnam 1995, 67).

In Table 5, we report the effects of NEP status on behavior and attitudes of stakeholders that reflect the basis for cooperation. Here, we shift our level of analysis from clans to dyads and individuals. We asked each survey respondent to identify up to three discussants, and then asked the respondent several questions about each discussant. Hence, each dyad consists of a respondentdiscussant pair, and each respondent can contribute up to three dyads to the analysis. We first discuss the top panel of Table 5 (labeled "network-related variables"), which uses dyads as the unit of analysis.

In the first row of Table 5, we find that the interactions between respondents and their discussants are more frequent in NEP estuaries. The average interaction in non-NEP estuaries is about twice per month, which increases by ten percent in NEP estuaries. In both cases, 
TABLE 5 NEP Status Affects Behavior and Attitudes

\begin{tabular}{|c|c|c|}
\hline & $\begin{array}{c}\text { Coefficient } \\
\text { (standard error) }\end{array}$ & Significance \\
\hline \multicolumn{3}{|c|}{ Network-Related Variables } \\
\hline \multicolumn{3}{|c|}{ Frequency of Contact } \\
\hline NEP status & $.24(.06)$ & .00 \\
\hline Lambda & $-.00(.05)$ & .98 \\
\hline Constant & $1.98(.04)$ & .00 \\
\hline $\mathrm{R}^{2}$ & .02 & \\
\hline \multicolumn{3}{|c|}{ Ideological Distance } \\
\hline NEP status & $.00(.08)$ & .50 \\
\hline Lambda & $.03(.07)$ & .63 \\
\hline Constant & $1.14(.06)$ & .00 \\
\hline $\mathrm{R}^{2}$ & .00 & \\
\hline \multicolumn{3}{|c|}{ Attitudes Reflecting Cooperation } \\
\hline \multicolumn{3}{|c|}{ Fairness of Policies } \\
\hline NEP status & $.14(.03)$ & .00 \\
\hline Lambda & $-.00(.02)$ & .85 \\
\hline Constant & $.53(.02)$ & .00 \\
\hline $\mathrm{R}^{2}$ & .06 & \\
\hline \multicolumn{3}{|c|}{ Own Interests Represented } \\
\hline NEP status & $.10(.03)$ & .00 \\
\hline Lambda & $-.00(.02)$ & .90 \\
\hline Constant & $.58(.02)$ & .00 \\
\hline $\mathrm{R}^{2}$ & .06 & \\
\hline \multicolumn{3}{|c|}{ Effectiveness of Policy } \\
\hline NEP status & $.10(.03)$ & .00 \\
\hline Lambda & $.05(.02)$ & .03 \\
\hline Constant & $.49(.02)$ & .00 \\
\hline $\mathrm{R}^{2}$ & .09 & \\
\hline \multicolumn{3}{|c|}{ Likelihood of Local Resolution } \\
\hline NEP status & $.13(.03)$ & .00 \\
\hline Lambda & $.03(.03)$ & .30 \\
\hline Constant & $.41(.02)$ & .00 \\
\hline $\mathrm{R}^{2}$ & .05 & \\
\hline
\end{tabular}

Source: Survey of NEP and non-NEP stakeholders; independent variables: see Table 1.

Table notes:

1. Significance levels for NEP status are one-tail, since we have hypothesized direction. For lambda, two-tailed.

2. The frequency of interaction and the ideological distance are based on dyads. The other measures are individual level variables. For a complete wording of the questions see Appendix B.

3. We asked respondents to name the people they talked with about estuary problems and policies. We then asked them to tell us how often they spoke with each of the people they named (with a maximum of three people). The categories were daily, weekly, monthly, or a few times per year. We used these categories as a dependent variable in an ordered probit. However, treatment corrected models for ordered probit models are not easily estimated. Therefore we report treatment corrected OLS estimates using the 1-4 category scale as the dependent variable. Note that the magnitude of the NEP effect was larger in the ordered probit estimation than in the other approaches. Ordered probit coefficients must be rescaled in order to be compared with OLS coefficients (Winship and Mares 1984) Following Winship, the adjusted coefficients are .28 for the frequency of contact and .18 for the number of allies. 
this frequency indicates that these specialized ties are all "weak ties." 10 More frequent interactions among weak ties can cement relationships between individuals and actually increase the flow of highly specialized information (see, e.g., Provan and Milward 1995).

In the next row of Table 5, we report the "ideological" or "policy distance" between respondents and their discussants. In our survey, we asked respondents to place themselves on a seven-point development/environment scale. We then asked respondents to place each of their discussants on the same scale. ${ }^{11}$ We found no differences between respondents in the NEP versus the non-NEP area.

This result points to some differences between the networks we observe and advocacy coalitions. Advocacy coalitions develop when small clans opportunistically united for continuing policy battles gradually expand and develop intensive linkages and shared beliefs, values, and policy goals (see Sabatier and Jenkins-Smith 1993; Zafonte and Sabatier 1998). In contrast, the network contacts illustrated in Figures 1 and 2 suggest a less-divided policy arena with contacts linking people who occupy different positions of authority or political influence in estuary politics. The lack of observed difference in ideology suggests that the expanded contacts nurtured by the NEP are randomly distributed across the ideological spectrum. Combined with the relatively weak evidence that clans in NEPs unite environmental and development interests, our results suggest that the NEP's goal of spanning ideological divides is considerably more difficult than the goal of coordinating activities across existing governmental authorities.

In the lower panel of Table 5, we compare the average scores of respondents in NEP and non-NEP areas on a range of attitudes that we believe reflect the level of cooperation found in an area, where individual respondents are the units of analysis instead of dyads. In each of these measures, the treatment effects model demonstrates that respondents in the NEPs have more cooperative attitudes than respondents in non-NEPs. For example, stakeholders

\footnotetext{
${ }^{10}$ In the analysis of informational networks, Granovetter (1985) has identified the strength of weak ties-that is, for introducing new information into a network, people often get the best information from people they interact with infrequently. For example, family members represent the strongest (most frequent) ties and all members of a family often possess the same information. Thus a network consisting of only strong ties often contains the least information. As the relatively infrequent interactions indicate, we are not dealing with strong ties. On the "weakness of strong ties" see Granovetter 1985, Knoke 1990, Huckfeldt and Sprague 1995, or Schneider et al. 1997b.

${ }^{11}$ Specifically we asked respondents "how would you describe your policy orientation on estuary issues when tradeoffs between environmental protection and economic development are important? Please use a 1 to 7 scale, where 1 means pro-development, 4 means neutral, and 7 means pro-environment.
}

in the NEP are more likely to believe that decision making is fair and that their interests are well represented, and they are also more likely to believe that the policies enacted in the estuary will significantly improve environmental conditions. Finally, respondents in the NEP are less likely to think about taking disputes outside the partnership, for example, by engaging in litigation.

\section{Conclusions: Government Can Help Build Consensual Institutions}

Our inquiry focuses on the development of networks that accompany new regional attempts to resolve estuary problems not contained within the boundaries of established government authority. The United States has several formal regional institutions created primarily in the 1970s to manage the environment, including the Delaware River Basin Commission, the California Coastal Commissions, and the San Francisco Bay Conservation and Development Commission. However, these high profile examples represent a very small subset of all environmental authorities. NEPs represent a much more widespread and, in many ways, more ambitious agenda for creating new forms of regional government.

These new forms of governance not only involve actors from different levels of government (the hallmark of earlier regional authorities), but also seek to integrate experts and, more importantly, a more diverse set of stakeholders into policy deliberations. They do not possess the formal powers vested in earlier authorities, but rather are designed as forums for discussing problems, developing trust, and formulating policy ideas to be implemented by the existing agencies. And rather than being designed as hierarchical agencies, these new forms of regional governance are marked by their reliance on networks that provide the foundation for collaborative agreements and other forms of cooperation. Our empirical research focuses specifically on boundary-spanning networks that encourage cooperative solutions to collective action problems like those involved in governing estuaries by sharing information about policy alternatives, enhancing the scope of negotiation, and reducing the enforcement and monitoring costs of cooperative agreements.

Specifically, we argued that federal programs like the NEP can help overcome the second-level collective action problems involved with network development, by providing funding, encouraging broader participation, establishing a focal policy arena with statutory legitimacy, disseminating information on successful versus unsuccessful approaches, and creating successful examples of 
regional institutional development. Our empirical analysis found that networks in the NEP areas are indeed more extensive, span more levels of government, integrate more experts into policy discussions, nurture stronger interpersonal ties between stakeholders, and create greater faith in the procedural fairness of local policy, thus laying the foundation for a new form of cooperative governance.

Our analysis of networks reflects Thatcher's argument that "a critical factor for public policy is the role of the state in establishing, supporting, or excluding actions [within networks], rules for their behavior and the distribution of resources" (1998, 403). By exploring the positive role that federal and state programs can play in enhancing local capacity to govern, we supplement Ostrom's (1990) exploration of the potential adverse effects of central governments on local institutions that govern the commons. Perhaps the most important remaining task for understanding the role of policy networks in providing a regional integration of governance within an unruly federalist system is the systematic exploration of the impact of networks on the policy outputs and outcomes of agencies involved in local networks.

\section{Appendix A}

TABLE A.1 Survey Response Rates by Estuary and Instrument Type

\begin{tabular}{|c|c|c|c|}
\hline & \multicolumn{3}{|c|}{ NEP Estuaries } \\
\hline Estuary & Mail & Telephone & Snowball \\
\hline Albemarle-Pamlico, NC & $20 / 101(20 \%)$ & $35 / 81(43 \%)$ & N/A \\
\hline Barnegat Bay, NJ & $34 / 115(30 \%)$ & $37 / 81(46 \%)$ & N/A \\
\hline Casco Bay, ME & $17 / 42(40 \%)$ & $14 / 25(56 \%)$ & N/A \\
\hline Charlotte Harbor, FL & $40 / 137(29 \%)$ & $57 / 97(59 \%)$ & N/A \\
\hline Corpus Christi, TX & $45 / 141(32 \%)$ & $57 / 94(61 \%)$ & N/A \\
\hline Delaware Inland Bays, DE & 28/92 (30\%) & $27 / 64(42 \%)$ & N/A \\
\hline Long Island Sound, NY & $22 / 101(22 \%)$ & $33 / 77(43 \%)$ & N/A \\
\hline Lower Columbia River, WA/OR & $23 / 65(35 \%)$ & $21 / 37(57 \%)$ & N/A \\
\hline Maryland Coastal Bays, MD & $27 / 100(27 \%)$ & $29 / 61(48 \%)$ & N/A \\
\hline Mobile Bay, AL & $33 / 105(31 \%)$ & $33 / 66(50 \%)$ & N/A \\
\hline New Hampshire Estuaries, NH & $26 / 73(36 \%)$ & $33 / 45(73 \%)$ & N/A \\
\hline Tampa Bay, FL & $32 / 100(32 \%)$ & $29 / 68(43 \%)$ & N/A \\
\hline \multirow[t]{2}{*}{ Total } & $347 / 1172(30 \%)$ & $405 / 796(51 \%)$ & N/A \\
\hline & \multicolumn{3}{|c|}{ Non-NEP Estuaries } \\
\hline Estuary & Mail & Telephone & Snowball \\
\hline Apalachicola Bay Estuary & N/A & $17 / 22(77 \%)$ & $16 / 18(89 \%)$ \\
\hline Atchafalaya Bay Estuary & N/A & $20 / 23(87 \%)$ & $9 / 16(56 \%)$ \\
\hline Cape Fear River Estuary & N/A & $19 / 34(56 \%)$ & $10 / 16(63 \%)$ \\
\hline Gray's Harbor Estuary & $\mathrm{N} / \mathrm{A}$ & $24 / 35(69 \%)$ & $5 / 6(83 \%)$ \\
\hline Lower Saint John's River Estuary & N/A & $26 / 39(67 \%)$ & $10 / 19(53 \%)$ \\
\hline Martha's Vineyard Estuary & $\mathrm{N} / \mathrm{A}$ & $14 / 31(45 \%)$ & $5 / 10(50 \%)$ \\
\hline Penobscot Bay Estuary & N/A & $22 / 42(52 \%)$ & $6 / 10(60 \%)$ \\
\hline Pensacola Bay Estuary & N/A & $25 / 26(96 \%)$ & $16 / 21(76 \%)$ \\
\hline Saco Bay Estuary & N/A & $26 / 42(62 \%)$ & 9/9 (100\%) \\
\hline St Andrew's Bay Estuary & N/A & $28 / 49(57 \%)$ & $5 / 8(63 \%)$ \\
\hline Total & & $221 / 343(64 \%)$ & $91 / 133(69 \%)$ \\
\hline
\end{tabular}

Note: Entries in cells are the number of surveys completed divided by the total sample number in each estuary, for each type of survey instrument. Response percentages are in parentheses. Response rates include respondents who were ineligible because they were not active in the estuary in the 12 months preceding the survey, or who had incorrect contact information. Ineligible respondents constitute the bulk of non-respondents, hence the refusal rate is substantially lower than the response rates reported above. 


\section{Appendix B Description and Source of Variables Used}

Table 1: Estuary Characteristics

Stress on Estuary

NOAA Expert Opinion study, Coastal Assessment

Framework, NOAA

Population Density (000)

1990 Census population per square mile, in thousands

Population

1990 census population in primary estuary

Prior Federal Program (SWCD)

Number of soil and water conservation districts within estuary

Previous Partnerships

Number of watershed partnerships established prior to 1990 , as reported in survey by Conservation

Technology Information Center (CTIC). 1997.

"National Watershed Network: Know Your

Watershed." http//:www.ctic.purdue.edu.

Proportion Black

Proportion of blacks among total 1990 census

Area

population in primary estuary

Measured in thousands of square miles

Tables 2-5: Networks and Attitudes

Frequency of Contact

What was the frequency of your contact with [fill ALLY1] during the last 12 months? Would you say daily, weekly, monthly, or just a few times each year?

The following variables were all coded $0-10$ in our questionnaire, but converted to $[0,1]$ for analysis.

Ideological Distance

What is [fill ALLY1]'s policy orientation on estuary issues when tradeoffs between environmental protection and economic development are important? (1-7, pro-environment is high)

Fairness of Policies

Overall, the decision-making process in the partnership is fair to all stakeholders. (high $=$ agree)

Own Interests Adequately Represented

Your organization's interests and concerns are adequately represented in the partnership. $($ high $=$ agree $)$

Effectiveness of Policy

How likely are the proposed or agreed upon management actions to significantly improve the problems of your estuary? (high = likely)
Likelihood of Local Resolution

Suppose conflicts arise in the next year. Do you think that conflicts can be resolved to the satisfaction of your organization within the partnership, or do you think your organization will need to shift the dispute to courts, political, or other administrative arenas? (high $=$ keep conflict within partnership)

\section{Appendix C Non-Random Selection and Treatment Effects Regression}

The quasi-experimental design in this article compares network characteristics in 12 estuaries with the NEP to 10 without the NEP. As with any quasi-experimental design, a critical question is whether or not the non-random selection of respondents into experimental (NEP) and control (non-NEP) groups biases conclusions about the effect of the experimental treatment. As noted in the body of this article, EPA's selection process for NEP estuaries may have focused on those estuaries that already had welldeveloped networks for collective action. To the extent this is true, the differences between NEP and non-NEP estuaries cannot be attributed to the valued-added from the NEP institution itself.

We used two strategies to address this problem. First, we tried to match NEP and non-NEP estuaries on a variety of criteria: geographic proximity, watershed condition, agricultural runoff potential, population density, and per capita income. Unfortunately, the geographic distribution and limited number of NEP estuaries makes it difficult to find matching non-NEP estuaries with directly comparable conditions within the same region. As evident in Table 1, NEP and non-NEP estuaries differ on a variety of environmental, socio-demographic, and institutional factors. The EPA seemed to be selecting more populous estuaries that have comparatively high levels of economic/institutional development and environmental threats. For example, in the Mid-Atlantic region, virtually all of the well-defined estuaries are part of the NEP or the Chesapeake Bay Program. In the Gulf of Mexico, the most developed estuaries are already in the NEP program, leaving only some of the less-developed areas for comparison. Consequently, the primary criterion we used to match estuaries was geographic proximity. We argue geographic proximity is the most important of the variables, because picking estuaries from different regions with very similar socio-demographic or institutional characteristics would sacrifice other regional similarities like political culture 
and type of ecosystem (e.g., it would be very hard to compare an NEP estuary in the Gulf of Mexico to a nonNEP estuary in the North Atlantic, even if they had similar population densities).

Since it was impossible to match NEP and non-NEP estuaries on all relevant criteria, the second strategy we use to address non-random selection is treatment effects regression. This common problem of quasi-experimental research designs is explained at length in Achen (1986). In a manner similar to Heckman selection bias models, treatment effects models use a two-step procedure to model the NEP dummy variable as an endogenous variable (Greene 1999; Maddala 1983). The presence of the NEP is modeled as a probit selection equation, where the NEP is observed if some underlying latent variable representing the capacity for collective action $\left(C_{i}\right)$ is greater than zero:

$$
\begin{aligned}
C_{i}^{*} & =\boldsymbol{\gamma}^{\prime} \mathbf{w}_{i}+u_{i} \\
N E P_{i} & =1 \text { if } C_{i}^{*}>0,0 \text { otherwise }
\end{aligned}
$$

The treatment effects model controls for nonrandom selection by directly entering estuary characteristics as independent variables $\left(\mathbf{w}_{i}\right)$ in the selection equation. Following Heckman's two-step procedure, as implemented by LIMDEP, the estimated inverse Mills ratio from the selection equation is then included in the regression outcome equation for only the survey respondents (Achen 1986; Greene 1999; Maddala 1983). The standard errors are also corrected as suggested by Greene (1999).

The estimated lambda coefficient is the diagnostic statistic for the consequences of non-random selection; if lambda is significantly different from zero, then nonrandom selection is biasing the coefficient for the NEP dummy. In addition, the presence of lambda corrects the estimated coefficient for the NEP dummy for potential biased. By controlling for non-random selection of the NEP, we can isolate the value-added impact of the NEP on network quality over and above the process of selecting estuaries into the program. Because Heckman's procedure is not fully efficient, there is a greater chance of making a Type II (beta) error in testing the hypothesis that the regression coefficients are greater than zero. Hence, conclusions based on standard definitions of statistical significance are conservative.

Since selection of the treatment occurs at the estuary level rather than at the level of survey respondent, our actual procedures required modifications of the standard selection procedure in LIMDEP. Instead of restricting the selection equation to the 22 estuaries in our survey, which would not provide sufficient variance for probit analyses, we included data for all 105 major estuaries in NOAA's Coastal Assessment and Data Synthesis System. The inverse Mills ratio (lambda) for each estuary is then associated with each observation from the estuary. The estuary is the unit of observation for analyses in Tables 2 and 3, the clan in Table 4, and the dyad and individual respondent in Table 5 .

In order to utilize LIMDEP's routine for correcting standard errors associated with the treatment effects model (Greene 1999), the data set we used actually entered all estuary data for each case in the outcome equation, and added one case for each of the 85 estuaries with missing survey information. We then weighted the data in each of the 22 surveyed estuaries by $1 / \mathrm{n}$, where $\mathrm{n}$ represents the number of observations in the estuary. This ensured that the selection equation exactly replicated the results of a probit estimation based on the original 105 estuary units. We thank Professor Greene for altering the weighting feature of LIMDEP to make this estimation procedure possible.

\section{References}

Achen, Christopher H. 1986. The Statistical Analysis of QuasiExperiment. Berkeley: University of California Press.

Arabie, Phipps, and Yoram Wind. 1994. "Marketing and Social Networks." In Advances in Social Network Analysis, ed. Stanley Wasserman and Joseph Galaskiewicz. Thousand Oaks, CA: Sage.

Bardach, Eugene. 1998. Getting Agencies to Work Together: The Practice and Theory of Managerial Craftsmanship. Washington, DC: The Brookings Institution.

Beatley, Timothy. 1991. Preserving Biodiversity Through the Use of Habitat Conservation Plans. Washington, DC: Urban Land Institute.

Beatley, Timothy. 1992. "Balancing Urban Development and Endangered Species: The Coachella Valley Habitat Conservation Plan.” Environmental Management 16(1):7-19.

Burroughs, Richard H., and Tim W. Clark. 1995. "Ecosystem Management: A Comparison of Greater Yellowstone and Georges Bank.” Environmental Management 19(5):649-63.

Burt, Ronald S. 1983. "Studying Status/Role Sets Using Mass Surveys." In Applied Network Analysis, ed. Ronald S. Burt. Beverly Hills: Sage.

Burt, Ronald S. 1987. "Social Contagion and Innovation: Cohesion versus Structural Equivalence." American Journal of Sociology 92(6):1287-335.

Coglianese, Cary. 1997. "Assessing Consensus: The Promise and Performance of Negotiated Rulemaking." Duke Law Journal 46(6):1255-350.

Granovetter, Mark. 1974. Getting a Job: A Study of Contacts and Careers. Cambridge: Harvard University Press.

Granovetter, Mark. 1985. "Economic Action and Social Structure: The Problem of Embeddedness." American Journal of Sociology 91(3):481-510. 
Greene, William H. 1999. Econometric Analysis. $4^{\text {th }}$ ed. New York: Prentice-Hall.

Hartig, John H., and Michael A. Zarull. 1992. Under RAPs: Towards Grassroots Ecological Democracy in the Great Lakes Basin. Ann Arbor: University of Michigan Press.

Heclo, Hugh. 1978. "Issue Networks and the Executive Establishment." In The New American Political System, ed. Anthony King. Washington, DC: American Enterprise Institute.

Huckfeldt, Robert, and John Sprague. 1995. Citizens, Politics and Social Communication: Information and Influence in an Election Campaign. New York: Cambridge University Press.

John, DeWitt. 1994. Civic Environmentalism. Washington, DC: Congressional Quarterly Press.

Knoke, David. 1990. Political Networks: The Structural Perspective. Cambridge: Cambridge University Press.

Knoke, David, Franz Urban Pappi, Jeffrey Braodbent, and Yutaka Tsujinaka. 1996. Comparing Policy Networks. Cambridge: Cambridge University Press.

Knoke, David, and James H. Kuklinski. 1991. "Network Analysis: Basic Concepts." In Markets, Hierarchies \& Networks: The Coordination of Social Life, ed. Grahame Thompson, Jennifer Frances, Rosalind Levacic, Jeremy Mitchell. London: Sage.

Konig, Thomas, and Thomas Brauninger. 1998. "The Formation of Policy Networks." Journal of Theoretical Politics 10(4):445-71.

Lin, Nan. 2001. Social Capital: A Theory of Social Structure and Action. London and New York: Cambridge University Press.,

Lubell, Mark, Mark Schneider, John Scholz, and Mihriye Mete. 2002. "Watershed Partnerships and the Emergence of Collective Action Institutions." American Journal of Political Science, 46(1):148-63.

MacKenzie, Susan Hill. 1996. Integrated Resource Planning and Management: The Ecosystem Approach in the Great Lakes Basin. Washington, DC: Island Press.

Marsden, Peter V. 1985. "Latent Structure Models for Relationally Defined Social Classes." American Sociological Review 90(5):1002-21.

Marsh, Lindell L., and Peter L. Lallas. 1995. "Focused, SpecialArea Conservation Planning: An Approach to Reconciling Development and Environmental Protection." In Collaborative Planning for Wetlands and Wildlife: Issues and Examples, ed. Douglas R. Porter and David A. Salvesen. Washington, DC: Island Press.

Melbeck, Christian. 1998. "Comparing Local Policy Networks.” Journal of Theoretical Politics 10(4):531-52.

Ostrom, Elinor. 1972. "Metropolitan Reform: Propositions Derived from Two Traditions." Social Science Quarterly 53(4):474-93.

Ostrom, Elinor. 1990. Governing the Commons: The Evolution of Institutions for Collective Action. Cambridge and New York: Cambridge University Press.
O’Toole, Laurence J., Jr. 1997. "Implementing Public Innovations in Network Settings." Administration and Society 29(2):115-38.

Peterson, Paul. 1995. The Price of Federalism. Washington DC: The Brookings Institution.

Provan, Keith G., and H. Brinton Milward. 1995. "A Preliminary Theory of Interorganizational Network Effectiveness: A Comparative Study of Four Community Mental Health Systems." Administrative Science Quarterly 40(1):133.

Putnam, Robert D. 1995. "Bowling Alone: America's Declining Social Capital." Journal of Democracy 6(1):65-78.

Rabe, Barry G. 1996. "An Empirical Examination of Innovations in Integrated Environmental Management: The Case of the Great Lakes Basin." Public Administration Review 56: 372-81.

Rabe, Barry G., and Janet B. Zimmerman. 1997. Sustainability in a Regional Context: The Politics of Ecosystem Management in the Great Lakes Basin. Presented at the 1997 Annual Meeting of the Midwest Political Science Association.

Rauch, James E., and Alessandra Casella, eds. 2001. Networks and Markets. New York: Russell Sage Foundation.

Sabatier, Paul, and Hank Jenkins-Smith, eds. 1993. Policy Change and Learning: An Advocacy Coalition Approach. Boulder: Westview Press.

Schneider, Mark. 1989. The Competitive City: The Political Economy of Suburbia. Pittsburgh: University of Pittsburgh Press.

Schneider, Mark, Paul Teske, Christine Roch, and Melissa Marschall. 1997a. "Institutional Arrangements and the Creation of Social Capital: The Effects of School Choice." American Political Science Review 91(1):82-93.

Schneider, Mark, Paul Teske, Christine Roch, and Melissa Marschall. 1997b. "Networks to Nowhere: Segregation and Stratification in Networks of Information about Schools." American Journal of Political Science 41(4):1201-23.

Scott, John. 1991. Social Network Analysis. Thousand Oaks: Sage.

Thatcher, Mark. 1998. "The Development of Policy Network Analysis.” Journal of Theoretical Politics 10(4):389-416.

Wheeler, Douglas P. 1996. "Ecosystem Management: An Organizing Principle for Land Use.” In Land Use in America, ed. Henry L. Diamond and Patrick F. Noonan. Washington, DC: Island Press.

Winship, Christopher, and Robert D. Mare. 1984. "Regression Models with Ordinal Variables." American Sociological Review 49(4):512-25.

Wondolleck, Julia M., and Steven L. Yaffee. 2000. Making Collaboration Work: Lessons from Innovation in Natural Resource Management. Washington, DC: Island Press.

Zafonte, Matthew, and Paul Sabatier. 1998. "Shared Beliefs and Imposed Interdependencies as Determinants of Ally Networks in Overlapping Subsystems." Journal of Theoretical Politics 10(4):473-505. 